\title{
The primacy effect of the first feeding experience in the snapping turtle'
}

Two groups of hatchling snapping turtles, without prior feeding experience, were given a meal of either meat or worms. One week later each group was fed the food it had not experienced earlier. The following week each turtle was tested for its preference between the two foods. The two groups of turtles differed significantly in the direction of preferring the first fed food. However, the two foods did not have equal effects. This indicates that although the first feeding experience has a primacy effect, this experience interacts with natural preferences in influencing subsequent behavior.

Recent experimental studies have indicated that the concept of imprinting can be extended to include other than social behavior (Hess, 1964). A suggestion that this might be possible was made in 1956 by Thorpe.

A recent experiment by Burghardt \& Hess (1966) indicated that food imprinting may be operative in the snapping turtle, a species in which the possibility of classical parental imprinting is absent. In that study it was shown that hatchling turtles fed 12 small daily meals on each of two foods would prefer the diet of the first 12 days over the diet of the second 12-day period. It was felt that this finding satisfied the primacy attribute of imprinting (Hess, 1964).

In the present experiment the effects of only one meal on each of two foods was investigated.

\section{Subjects}

The Ss were 25 previously unfed snapping turtles (Chelydra serpentina) which hatched from a single clutch of eggs 16 days before the experiment commenced. The mother was caught in northwestern Indiana shortly before she laid her eggs in an outdoor pen.

\section{Apparatus and Procedure}

Shortly after hatching, each turtle was placed in a separate glass tank. Details concerning housing and the general experimental procedure are given in a previous report (Burghardt \& Hess, 1966).

The turtles were divided randomly into two groups. Group 1 contained 12 Ss and was first fed balls of horsemeat about $7 \mathrm{~mm}$ in diameter. Group 2 contained $13 \mathrm{Ss}$ and was first fed pieces of redworms (Eisenia foetida) about $1.7 \mathrm{~cm}$ long. The temperature was $25^{\circ} \mathrm{C}$ throughout the experiment.

A metal sheet restrained the turtles in one corner of the tank while the food was placed in the water in the center of each tank. Each $S$ in Group 1 received three balls of meat and each $S$ in Group 2 recelved three pieces of worm. If all three pieces of food were eaten, the $S$ was given additional pieces until it was satiated. Two Ss in Group I would not eat on this first day so the food was removed and presented again the following day. At this time they did eat; all subsequent work with these turtles was delayed one day. Seven days later the above procedure was repeated except that now Group 1 received worms and Group 2 received meat. All Ss were allowed $30 \mathrm{~min}$. in which to eat.

Exactly one week later each $S$ was tested in a choice situation for its preference of the two foods. The above procedure was followed except that a piece of worm and a ball of meat were placed in the center of the tank $2 \mathrm{~cm}$ apart. The relative position of the two foods was systematically varied from $S$ to $S$. Each $S$ was allowed to eat both foods but its first choice was noted.

The tanks were cleaned and refilled with $2 \mathrm{~cm}$ of aged water before the second feeding and before the choice test.

Results

The results are summarized in Table 1. All 12 initially meat-fed Ss chose the meat and eight of the 13 originally worm-fed Ss chose the worm. Therefore, 20 of the $25 \mathrm{Ss}$ selected the food which they first experienced. This result is highly significant ( $p<.005$, binomial test, $P=.5$ ). A Chi square test demonstrated significant differences between the two groups $\left(X^{2}=8.21\right.$, df $\left.=1, p<.01\right)$.

Table 1 also shows the number of pieces of food eaten by each group of Ss rounded off to the nearest integer. Group 1 and Group 2 ate about the same number of pieces in the first meal. Although the total number of pieces eaten by both groups in the second meal is almost identical with that of the first meal, it will be noticed that Group 1 ate less worms than it did meat whlle Group 2 ate more meat the second meal than it did worms the first meal. Along with this it should be noted that in the choice situa-

Table 1. Food preference by snapping turtles after one meal on each of two foods.

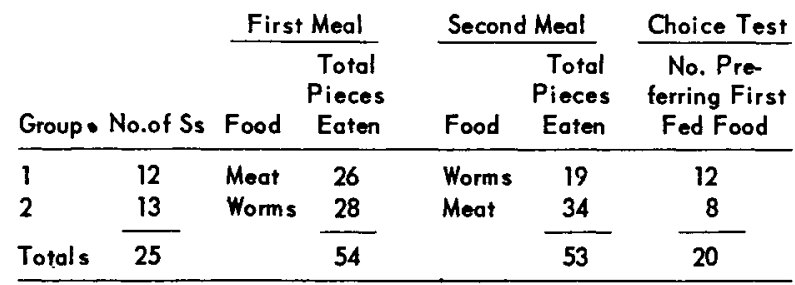


tion, Ss in Group 1 almost never showed any interest in the worm after eating the meat. Ss in Group 2, however, invariably attacked both foods in the $30 \mathrm{~min}$. test period.

Discussion

These results indicate that the primacy attribute of imprinting can be demonstrated in snapping turtles after only one meal. It also seems clear that there is something about the horsemeat which makes it more attractive to the turtles than worms, and that this leads to stronger "imprinting" to the meat. A dynamic relationship would appear to exist between natural preferences and the effects of early experience. This relationship is similar to the finding that colored models vary in their effectiveness as imprinting objects in chicks (Schaefer \& Hess, 1959).

To interpret these results on the basis of different motivational states on the first and second feeding periods does not appear tenable. The total amount of food eaten during both periods was almost the same. Group 2 ate more meat the second period than it ate worms the first period but still selected worms over meat. Indeed, Group 2 ate more meat than did Group 1, yet Group 1 overwhelmingly selected meat over worms in contrast to Group 2. A consistent explanation must consider the order in which the two foods were presented and in this particular instance the recency of reinforcement is not the critical factor.

Although this study is in agreement with the earlier study in which 12 small feedings were given on each food, it should not be thought that subsequent experience with different foods cannot alter the effects demonstrated here. The "reversibility" of sexual imprinting in doves has been shown (Klinghammer \& Hess, 1964; Klinghammer, 1965). However, the amount of subsequent experience needed to cancel out the short period of early experience can be considerable. Similarly, it is probable that an obliteration of the effects of early feeding in the snapping turtle will entail a period of subsequent experience greater than the initial experience, keeping in mind, of course, the different possible innate preferences for the foods involved.

Since the turtles in this experiment were older than those in the earlier experiment by almost a week it appears that a temporal critical period is not involved in the phenomenon demonstrated here.

The species generality of the primacy effects of early experience with food objects is far from clear. Rabinowitch (1966) has presented suggestive evidence for Herring and Ring-billed gulls, but since his birds were tested after experience with only one type of food the uniqueness of early over later experience was not demonstrated. More similar to the present and especially the earlier study of snapping turtles is the work of Bronson (1966) with rats. Although no primacy effect of early diet was noted with this mammalian form, there were enough variations in technique to make direct comparisons premature.

\section{References}

Bronson, G. Evidence of the lack of influence of early diet on aduit food preferences in rats. J. comp. physiol. Psychol., 1966, 62, $162-164$.

Burghardt, G. M., \& Hess, E. H. Food imprinting in the snapping turtle. Chelydra serpentina. Science, 1966, 151, 108-109.

Hess, E. H. Imprinting in birds. Science, 1964, 146, 1128-1139. Klinghammer, E. Imprinting in an altricial bird: the mourning dove (Zenaidura macroura). Amer. Zoologist, 1965, 5, 405 (Abstract).

Klinghammer, E., \& Hess, E. H. Imprinting in an altricial bird: the ring dove (Streptopelia risoria). Science, 1964, 146, 265-266.

Rabinowitch, $\mathbf{V}$. The role of early experience in the development of food habits in gull chicks. Bull. Ecol. Soc. Amer., 1966, 47, 144 (Abstract).

Schaefer, H., \& Hess, E. H. Color preferences in imprinting objects. Z. Tierpsychol., 1959, 16, 161-172.

Thorpe, W.H. Learning and instinct in animals. Cambridge: Harvard University Press, 1956.

\section{Note}

1. This investigation was supported in part by Public Health Service Research Grant 776, from the National Institute of Mental Health, awarded to Eckhard H. Hess. Erich Klinghammer generously supplied the gravid turtle. 